\title{
Microstructural Evolution of Alloy Powder for Electronic Materials with Liquid Miscibility Gap
}

\author{
I. OHNUMA,${ }^{1,3}$ T. SAEGUSA, ${ }^{1}$ Y. TAKAKU, ${ }^{1}$ C.P. WANG, ${ }^{2}$ X.J. LIU, ${ }^{2}$ \\ R. KAINUMA, ${ }^{1}$ and K. ISHIDA ${ }^{1}$
}

\begin{abstract}
1.-Department of Materials Science, Graduate School of Engineering, Tohoku University, Aobayama 6-6-02, Sendai 980-8579, Japan. 2.-Department of Materials Science and Engineering, Xiamen University, Xiamen 361005, China. 3.—e-mail: ohnuma@material.tohoku.ac.jp
\end{abstract}

The microstructure of powders that are applicable for electronic materials were studied for some systems in which there is a liquid miscibility gap. The characteristic morphologies of an egg-like core type and a uniform secondphase dispersion are shown in relation to the phase diagram, where thermodynamic calculations are a powerful tool for alloy design and the prediction of microstructure. Typical examples of microstructural evolution and properties of $\mathrm{Pb}$-free solders and Ag-based micropowders with high electrical conductivity produced by a gas-atomizing method are presented.

Key words: Liquid miscibility gap, powder, phase diagram, thermodynamic calculation

\section{INTRODUCTION}

Although a large variety of possible applications for monotectic alloys with a liquid miscibility gap is expected, ${ }^{1,2}$ there is an essential drawback for industrial processing during solidification because two liquids are generally of different density, which leads to rapid spatial phase separation due to buoyant forces under the Earth's gravitational field. ${ }^{1}$ Recently, we have shown that an egg-type core microstructure is obtained by conventional gas atomization, where the minor liquid phase always forms the core of the egg. A typical example of the egg-type microstructure is shown in Fig. 1a, which was obtained for a $\mathrm{Cu}-31.4 \mathrm{Fe}-3 \mathrm{Si}-0.6 \mathrm{C}$ (mass\%) alloy powder. ${ }^{3}$ This kind of morphology can be explained by Marangoni motion on the basis of the temperature dependence of the interfacial energy. ${ }^{4}$ Figure $1 b$ shows a schematic illustration of the microstructural evolution of an immiscible liquid particle, where the minor phase droplets rapidly move and assemble toward the center of the particle against the temperature gradient. Since this

(Received March 18, 2008; accepted July 28, 2008;

published online September 10, 2008) finding, extensive work has been carried out on the mechanism $^{5-7}$ of the formation of this egg-type microstructure, the role of interfacial energy, ${ }^{8}$ and bulk ingots with a core-type microstructure. ${ }^{9}$ Very recently, we performed phase field simulation of the microstructural evolution of immiscible liquid powder ${ }^{10}$ which permits the general treatment of composite powder with a core/shell structure. It is noted that an egg-type microstructure is obtained in epoxy resin, where a similar effect of interfacial tension gradient occurs. ${ }^{11}$

In this paper, the characteristic morphological features and properties of immiscible monotectic alloy systems, focusing on Pb-free solders and Ag-based micropowders with high electrical conductivity, are presented.

\section{EXPERIMENTAL PROCEDURE}

Alloy compositions of $\mathrm{Pb}$-free solders and Ag-base powders with a liquid miscibility gap were designed using the thermodynamic Alloy Database for MicroSolders (ADAMIS) database ${ }^{12,13}$ in combination with the Cu-based database. ${ }^{14}$ Figure 2 shows a schematic illustration of the relation between the microstructure of the powder and the phase diagram with a liquid-phase miscibility gap. An egg-type core 
(a) $\mathrm{Cu}-31.4 \mathrm{Fe}-3 \mathrm{Si}-0.6 \mathrm{C}$ (mass\%)
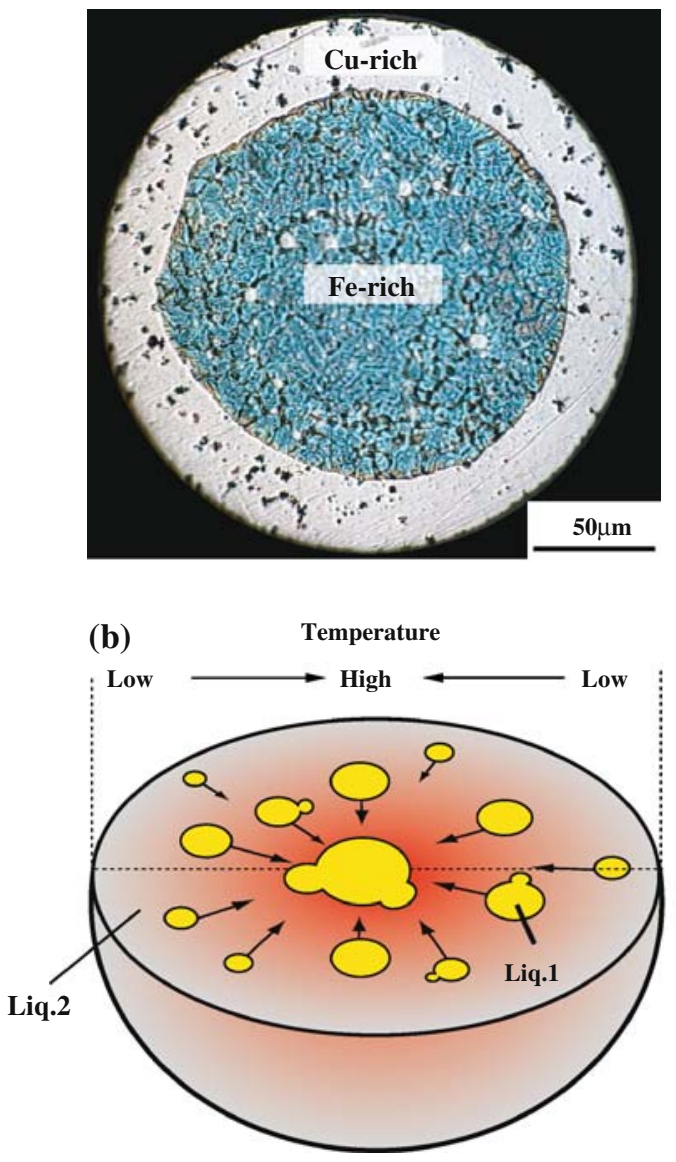

Fig. 1. (a) Microstructure of the Cu-31.4Fe-3Si-0.6C (mass\%) alloy powder and (b) schematic illustration demonstrating the microstructural evolution in the powder.

structure is formed when the composition is located in the middle portion of the miscibility gap, while the in situ composite shows that a fine second phase dispersed in the matrix is formed just inside both ends of the miscibility gap. Therefore, thermodynamic calculation of the liquid miscibility gap plays a key role in the microstructural evolution of a powder. Two types of $\mathrm{Pb}$-free solders were prepared: $\mathrm{Sn}-\mathrm{Al}-\mathrm{Cu}$ alloys, where the melting temperature of the Sn-rich periphery of the core/shell structure is about $230^{\circ} \mathrm{C}$, and $\mathrm{Bi}-\mathrm{Cu}$-base powders for hightemperature $\mathrm{Pb}$-free solders, where the melting temperature is about $270^{\circ} \mathrm{C}$. On the other hand, three kinds of Ag-based powders with high electrical conductivity, Ag-Cu-Ni, Ag-Cu-Co, and $\mathrm{Ag}-\mathrm{Cu}-\mathrm{Fe}$ alloys, were prepared. First, the mother alloys were melted in evacuated quartz capsules and then the ingots were melted again in a quartz nozzle surrounded by an induction coil. The powders were produced by atomization with high-pressure argon gas flow (5 MPa). These samples were mounted in epoxy resin and polished to examine their microstructure by optical microscopy and scanning election microscopy. Transformation temperatures were

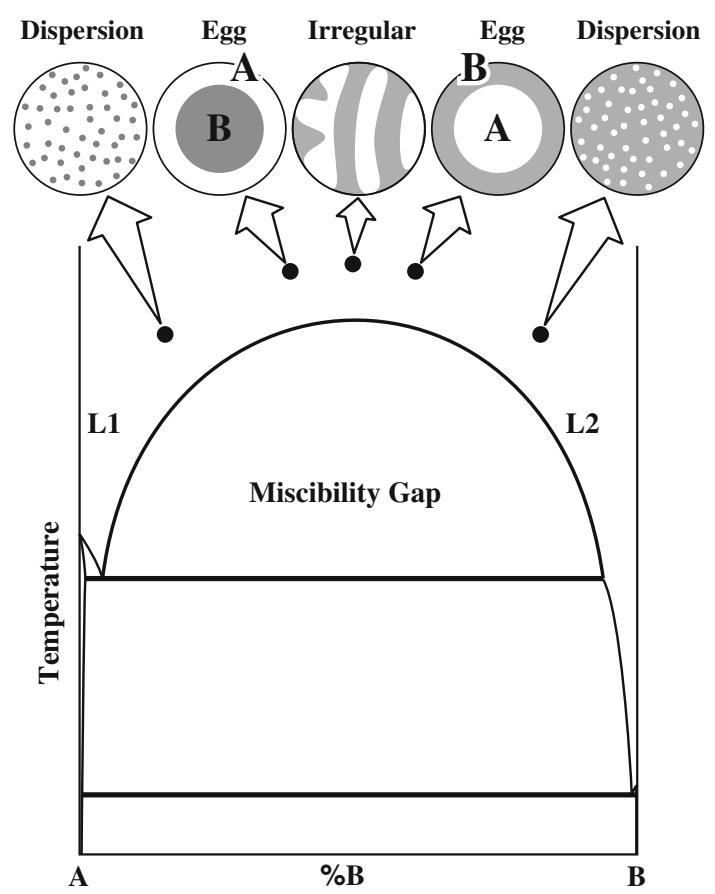

Fig. 2. Schematic illustration of the microstructural evolution of a powder related to a phase diagram with a liquid-phase miscibility gap.

determined by differential scanning calorimetry (DSC) with heating and cooling rates of $5-10 \mathrm{~K} / \mathrm{min}$. The composition of each phase in the alloy powders was determined by electron probe microanalysis (EPMA). Electrical resistance of Ag-based alloys was measured by the four-terminal method after the powders were compacted and sintered.

\section{RESULTS AND DISCUSSION}

\section{Powder of Pb-free Solders}

Many studies have been conducted to develop $\mathrm{Pb}$-free solders to replace the conventional $\mathrm{Pb}-\mathrm{Sn}$ eutectic alloy, and Sn-based solder alloys, such as $\mathrm{Sn}-\mathrm{Ag}-\mathrm{Cu}, \mathrm{Sn}-\mathrm{Cu}, \mathrm{Sn}-\mathrm{Zn}-\mathrm{Bi}$, and $\mathrm{Sn}-\mathrm{Zn}-\mathrm{Al}$, are now practically used for electronic packaging technology. In particular, microsolder balls are applied to the input/output terminal of ball grid arrays (BGAs), which has the advantage of having higher input/ output terminal density, smaller footprint, and higher reliability. ${ }^{15}$ However, thermal cycling caused by processing of circuit boards at high temperatures generates coarsened microstructures, which result in degradation due to creep and fatigue. To improve the mechanical properties, strengthening of the matrix by particles of intermetallic compounds has been proposed, ${ }^{16}$ in which mechanical mixing of the eutectic Sn-3.5Ag solder with $\mathrm{Cu}$ or $\mathrm{Ag}$ particles yields a characteristic microstructure with $\mathrm{Cu}_{3} \mathrm{Sn}$ and $\mathrm{Cu}_{6} \mathrm{Sn}_{5}$ or $\mathrm{Ag}_{3} \mathrm{Sn}$ dispersions, respectively. This kind of dispersion microstructure can be obtained by the in situ 
method, where the composition of the solder ball is designed to be located inside both ends of the liquid miscibility gap, as shown in Fig. 2. Figure 2 shows a schematic illustration of the microstructure formation through a two-liquid miscibility gap in a fictitious A-B binary system, in which the surface tension of each liquid element is assumed to be equivalent. According to the phase-field simulations of the microstructural evolution ${ }^{10,17}$ an irregular microstructure can be obtained when the volume fractions of the two liquid phases are almost equal. On the other hand, the liquid phase of the smaller volume fraction forms the core of the egg-type microstructure. In addition to the simulated results, it was found from experimental studies that the dispersion microstructure can be obtained.

An egg-type core solder ball has potential as a new type of BGA packaging because the core parts have a higher stiffness with a higher melting temperature for maintaining the distance between chips and substrates. Therefore, a $\mathrm{Cu}$ core ball is a candidate for high-power and high-performance applications. ${ }^{18} \mathrm{~A}$ smaller size of core ball, less than $100 \mu \mathrm{m}$, is required for the chip-scale package. In view of the difficulty of producing a $\mathrm{Cu}$ core ball with a size of $<100 \mu \mathrm{m}$, an egg-type core solder ball can be obtained by a very simplified fabrication method, as shown in Fig. 2. In this paper, two types of $\mathrm{Pb}$-free solder ball with $\mathrm{Sn}$-based and Bi-based alloys, which have melting temperatures of about $230^{\circ} \mathrm{C}$ and $270^{\circ} \mathrm{C}$, respectively, are presented.

Figure $3 \mathrm{a}$ and $\mathrm{b}$ shows the isothermal section phase diagrams of the Sn-Al-Cu ternary system at $700^{\circ} \mathrm{C}$ and $530^{\circ} \mathrm{C}$ where a stable miscibility gap appears in the Sn-rich corner. The vertical section phase diagram between $\mathrm{Sn}$ and the $70 \mathrm{Al}-30 \mathrm{Cu}$ (mass\%) section is shown in Fig. 3c. Based on these phase diagrams, Sn-27.8Al-10.9Cu (mass\%) alloy powder was prepared. Figure 4a shows the microstructure of the powder, which shows the egg-type core structure with a Sn-rich periphery. The approximate compositions of the periphery and core parts are 94Sn-5Al-1Cu (mass\%) and 17Sn-55Al$27 \mathrm{Cu}$ (mass\%), respectively. The DSC curve of the powder is shown in Fig. 4b. The first and large endothermic peaks appeared at about $230^{\circ} \mathrm{C}$ and $530^{\circ} \mathrm{C}$, which correspond to the melting temperatures of the Sn-rich periphery and the Al-rich core part, respectively. Therefore, the $\mathrm{Sn}-\mathrm{Al}-\mathrm{Cu}$ alloy is a candidate for $\mathrm{Pb}$-free solder balls possessing a medium melting temperature.

On the other hand, Bi-based alloys are candidates for high-temperature $\mathrm{Pb}$-free solders. Since the details of Bi-based solder properties such as phase relation, microstructure, interfacial reaction, and reliability have already been reported, ${ }^{19-21}$ only the typical microstructures of an egg-type core/shell and an in situ composite powder particles are shown, in Fig. 5a and b, respectively. The shell of egg-type particles and the matrix of the in situ composite consist of a Bi-rich phase which plays a role in
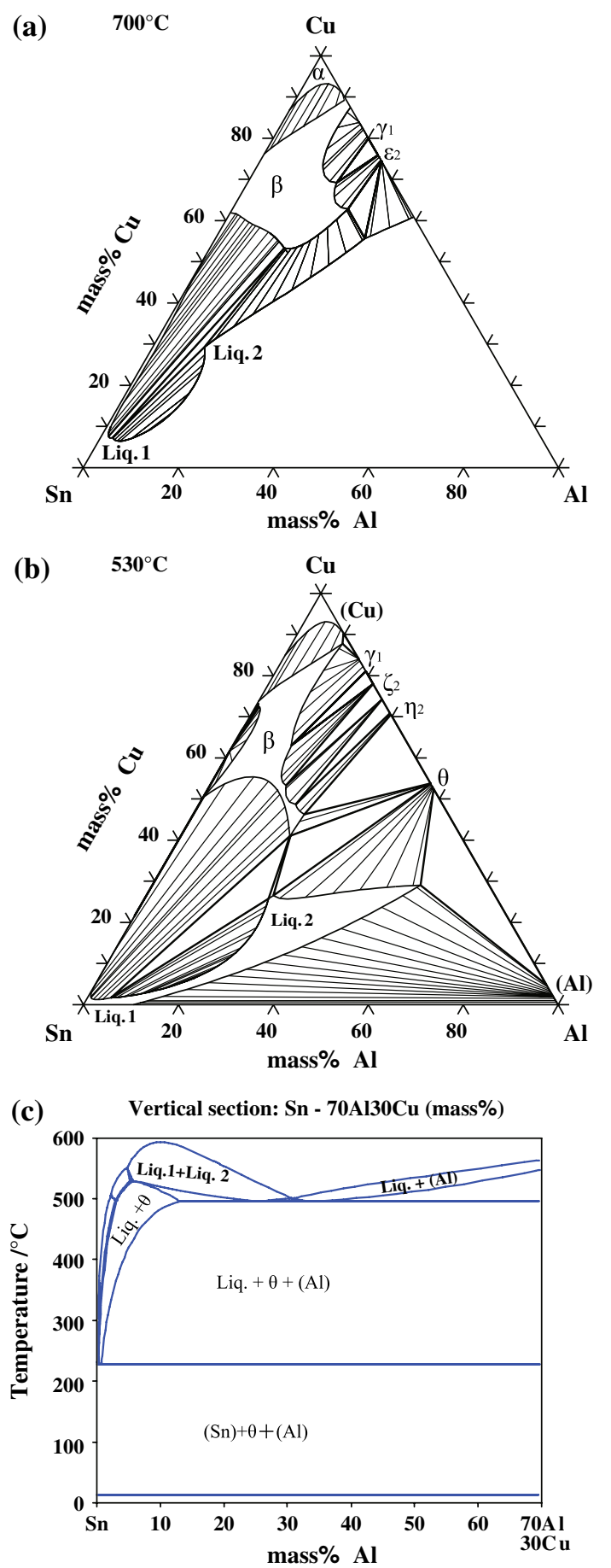

Fig. 3. Isothermal section phase diagrams of Sn-Al-Cu ternary system at (a) $700^{\circ} \mathrm{C}$ and (b) $530^{\circ} \mathrm{C}$, and (c) vertical section phase diagram between $\mathrm{Sn}$ and $70 \mathrm{Al}-30 \mathrm{Cu}$ (mass\%).

high-temperature solders. On the other hand, a $\mathrm{Cu}-\mathrm{Sn}$ intermetallic compound forms the core and dispersion particles, which are expected to improve their mechanical properties. The melting temperatures were found to be about $270^{\circ} \mathrm{C}$ and $730^{\circ} \mathrm{C}$, which correspond to those of the Bi-rich phase and the $\mathrm{Cu}_{3} \mathrm{Sn}$ compound. ${ }^{18}$ 
(a)

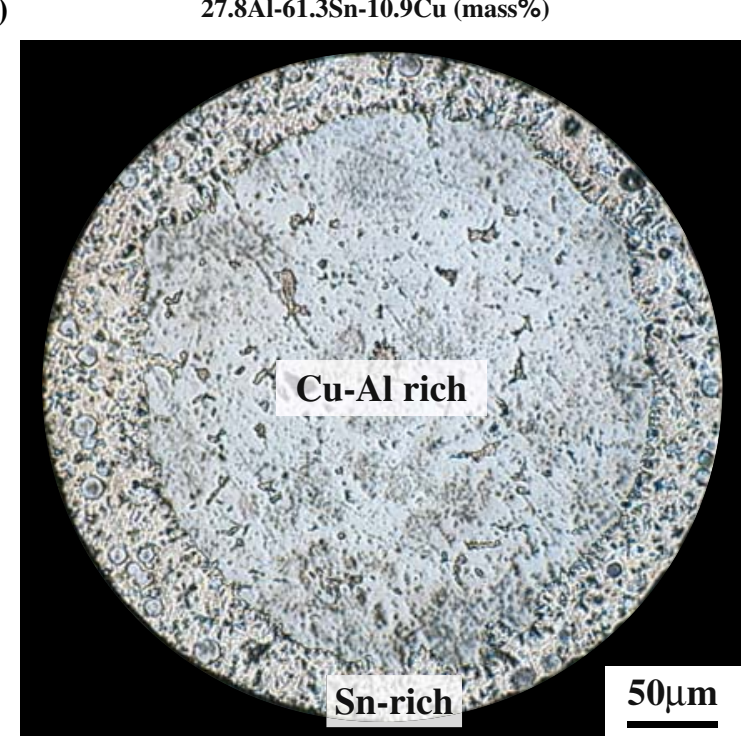

(b) DSC profile

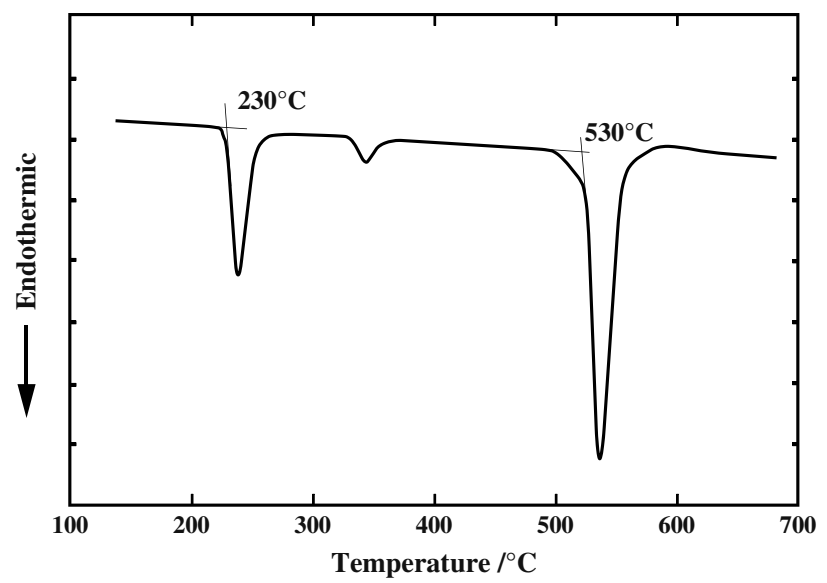

Fig. 4. (a) Microstructure and (b) heating curve of DSC measurement of Sn-27.8Al-10.9Cu (mass\%) alloy.

\section{Powder of Ag-based Electroconductive Filler}

Another application of immiscible powder materials is an electroconductive filler which can be used instead of pure silver powder. Because of the increasing cost of silver, it is necessary to reduce its use in conductive fillers. If the powder has an eggtype microstructure, whose shell and core are composed of Ag-based and other inexpensive alloys, respectively, silver consumption can be reduced effectively without detriment to the electric properties. Binary phase diagrams of the $\mathrm{Ag}-\mathrm{X}(\mathrm{X}=\mathrm{Ni}$, $\mathrm{Fe}$, and $\mathrm{Co}$ ) and $\mathrm{Ag}-\mathrm{Cu}$ systems show miscibility gaps in the liquid phase and in the fcc phase, respectively, which suggests that egg-type and fine dispersion structures of Ag-based alloys can be fabricated using a gas atomizing method. Figure 6 shows a calculated phase diagram of the $\mathrm{Ag}-\mathrm{Cu}-\mathrm{Ni}$ ternary system, in which three isotherms of a miscibility gap in liquid at $1500^{\circ} \mathrm{C}, 2000^{\circ} \mathrm{C}$, and $2500^{\circ} \mathrm{C}$

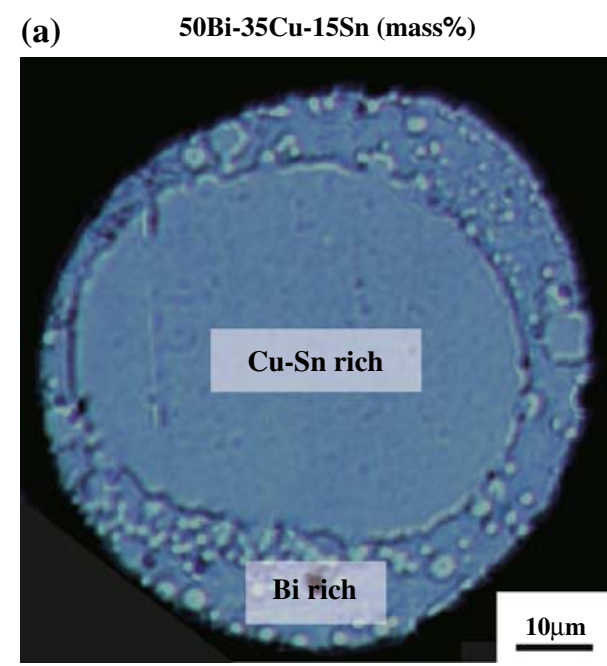

(b) 70Bi-20Cu-10Sn (mass\%)

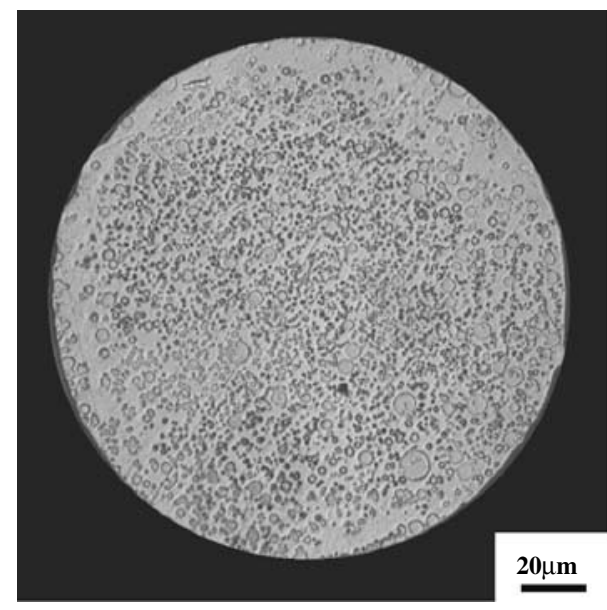

Matrix : Bi rich phase

Particles : Cu-Sn rich phase

Fig. 5. Microstructures of (a) 50Bi-35Cu-15Sn (mass\%) and (b) 70Bi-20Cu-10Sn (mass\%) powders.

are drawn. A vertical section phase diagram calculated along the dashed line superimposed on the ternary phase diagram in Fig. 6 is shown in Fig. 7. According to this phase diagram, the compositions of three alloys were designed: (a) Ag- $25 \mathrm{Cu}-10 \mathrm{Ni}$, (b) $\mathrm{Ag}-25 \mathrm{Cu}-50 \mathrm{Ni}$, and (c) Ag-25Cu-65Ni (at.\%). The first and third ones are expected to form an in situ composite microstructure and the obtained powders indeed show the expected morphology. The microstructure of the Ag- $25 \mathrm{Cu}-50 \mathrm{Ni}$ powder whose chemical composition is located around the middle of the miscibility gap shows the egg-type morphology as seen in Fig. 7b. In this alloy, the obtained microstructure consists of an fcc- $(\mathrm{Ni}, \mathrm{Cu})$ core surrounded by an fcc-(Ag) periphery even though the volume fraction of the Ag-rich liquid is smaller than that of the $(\mathrm{Ni}, \mathrm{Cu})$-rich one, which is inconsistent with the predicted microstructure shown in Fig. 2. Such a contradiction seems to be caused by the considerable difference of the liquid surface tension 


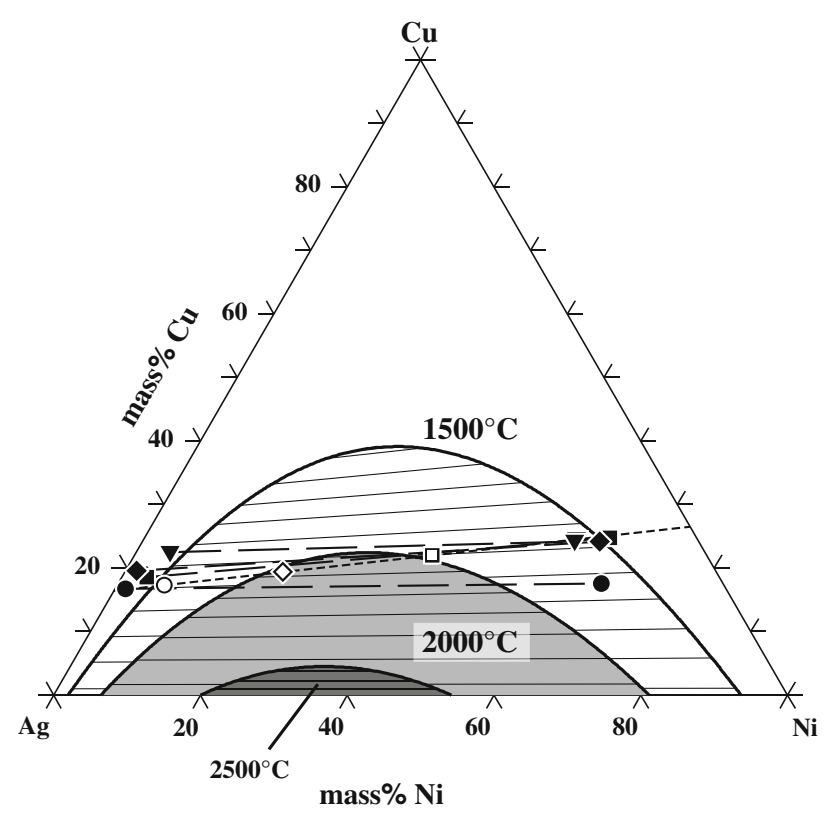

Fig. 6. The liquid miscibility gap in the Ag-Cu-Ni ternary system.

(a) $\mathrm{Ag}-25 \mathrm{Cu}-10 \mathrm{~N}$

(b) $\mathrm{Ag}-25 \mathrm{Cu}-50 \mathrm{Ni}$

(c) $\mathrm{Ag}-25 \mathrm{Cu}-65 \mathrm{Ni}$
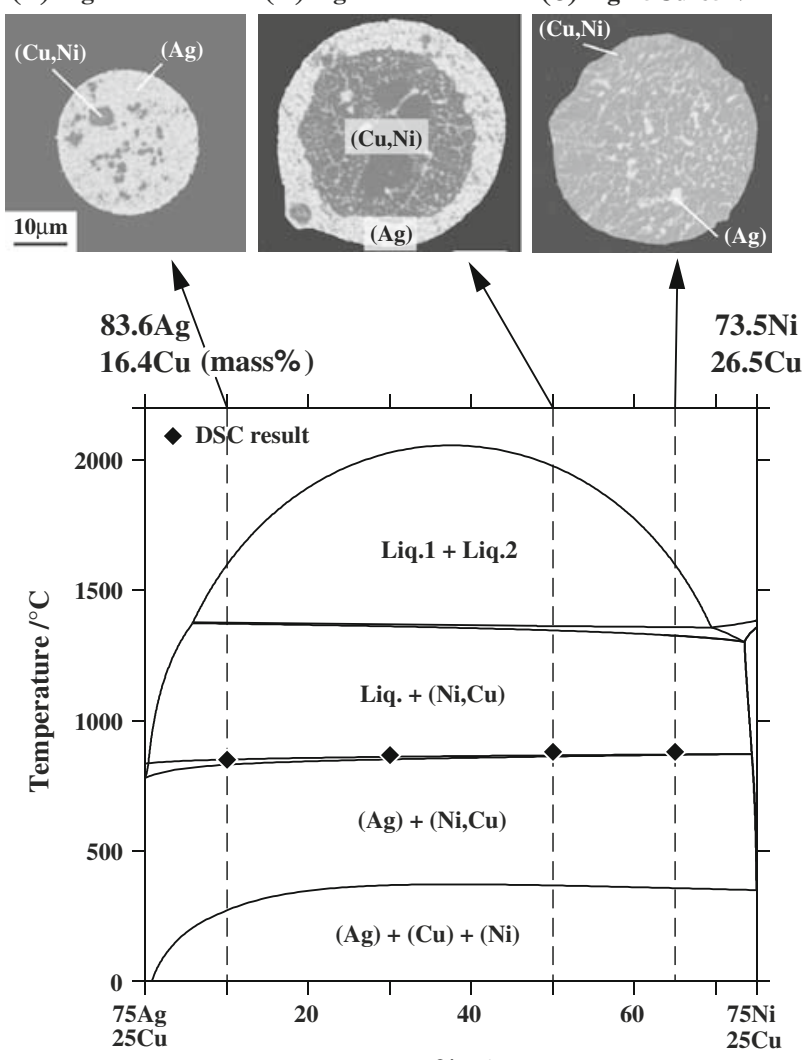

$26.5 \mathrm{Cu}$

at. $\% \mathrm{Ni}$

Fig. 7. Calculated vertical section phase diagram between 75Ag$25 \mathrm{Cu}$ and $75 \mathrm{Ni}-25 \mathrm{Cu}$ (at.\%) alloys and typical microstructures of gas-atomized powders. Results of DSC measurement, which represent the melting temperature of the Ag-rich liquid phase, are superimposed by solid diamonds.

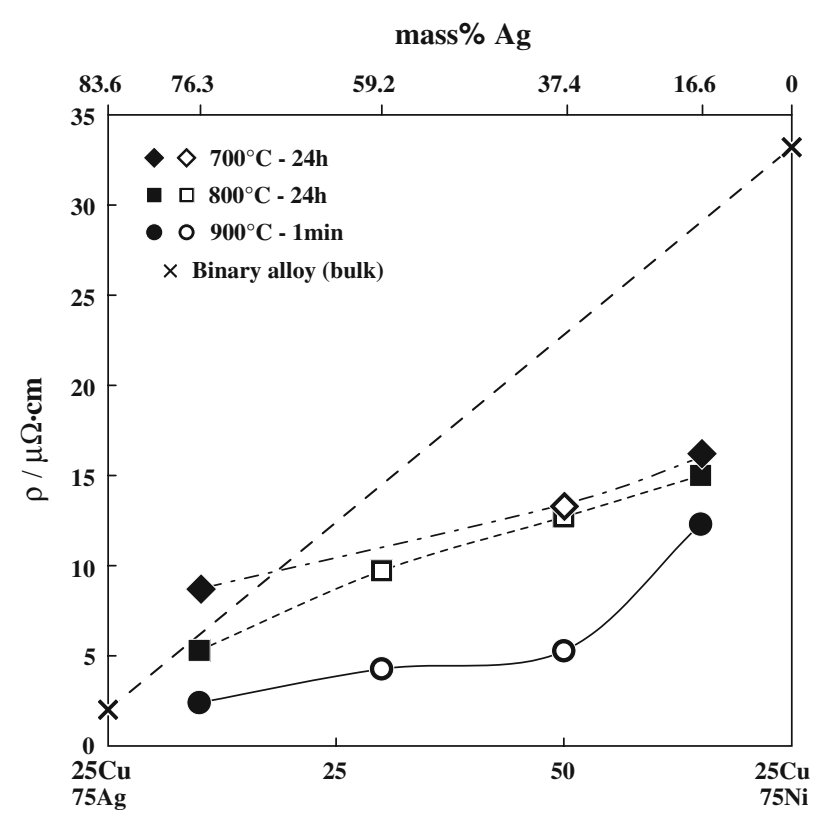

at.\% $\mathrm{Ni}$

Fig. 8. Electrical resistivity of $\mathrm{Ag}-25 \mathrm{Cu}-x \mathrm{Ni}(x=10,30,50,65)$ (at.\%) alloys with three sintering temperatures of $700^{\circ} \mathrm{C}, 800^{\circ} \mathrm{C}$, and $900^{\circ} \mathrm{C}$.

between $\mathrm{Ag}\left(895 \mathrm{~mJ} / \mathrm{m}^{2}\right.$ at $\left.1000^{\circ} \mathrm{C}\right)$ and $\mathrm{Ni}-\mathrm{Cu}$ alloy (Ni-20 mass\% Cu: $1700 \mathrm{~mJ} / \mathrm{m}^{2}$ at $1300^{\circ} \mathrm{C}$ ). ${ }^{22}$ This kind of egg-type microstructure with a Ag periphery is desirable for materials substituting for pure Ag in a conductive filler. The approximate compositions of the matrix and dispersion phases in Fig. 7a and $\mathrm{c}$ and of the periphery and core phases in Fig. $7 \mathrm{~b}$ are plotted on the ternary phase diagram in Fig. 6. Obtained results are coincident with the equilibrium relationship of the miscibility gap at $1500^{\circ} \mathrm{C}$, which indicates that the heating temperature in the quartz nozzle in the atomizing process surpassed $1500^{\circ} \mathrm{C}$. To evaluate the electrical conductivity of the $\mathrm{Ag}-\mathrm{Cu}-\mathrm{Ni}$ immiscible alloys, some powders were compacted and sintered. According to results of DSC measurement shown in Fig. 7, sintering conditions were chosen to be $700^{\circ} \mathrm{C}$ and $800^{\circ} \mathrm{C}$ for $24 \mathrm{~h}$ below the melting temperature, $T_{\mathrm{m}}$, of the Ag-rich phase, and $900^{\circ} \mathrm{C}$ for $1 \mathrm{~min}$ above $T_{\mathrm{m}}$. The compositions of four alloys were chosen between $75 \mathrm{Ag}-25 \mathrm{Cu}$ and $75 \mathrm{Ni}-25 \mathrm{Cu}$ (at.\%), whose specific resistances are $2 \mu \Omega / \mathrm{cm}$ and $33 \mu \Omega / \mathrm{cm}$, respectively. Most of the obtained resistivity data exhibited negative deviation from the mixing rule shown by the dashed line in Fig. 8. In particular, compacted samples processed by the liquid-phase sintering method at $900^{\circ} \mathrm{C}$ showed lower resistivity. In terms of decreasing $\mathrm{Ag}$ consumption, the $\mathrm{Ag}-25 \mathrm{Cu}-50 \mathrm{Ni}$ (at.\%) alloy contains only 37.4 mass\% $\mathrm{Ag}$ and possesses a relatively low specific resistance of 5.28 $\mu \Omega / \mathrm{cm}$. The microstructure of the $\mathrm{Ag}-25 \mathrm{Cu}-50 \mathrm{Ni}$ (at.\%) atomized particle consists of a $\mathrm{Cu}-\mathrm{Ni}$ core and a Ag-rich periphery. During liquid-phase sintering, 


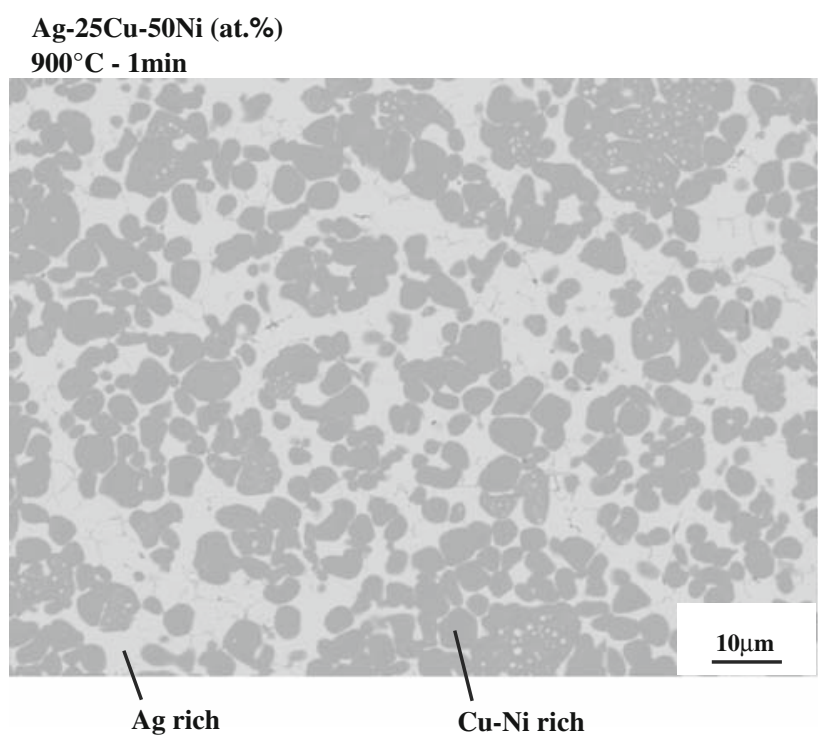

Fig. 9. Microstructure of $\mathrm{Ag}-25 \mathrm{Cu}-50 \mathrm{Ni}$ (at.\%) after sintering at $900^{\circ} \mathrm{C}$.

two microstructural evolutions occurred in the compacted sample: annihilation of voids and formation of percolation paths of the high-conductive Ag-rich phase as shown in Fig. 9, both of which caused a drastic decrease of the specific resistance, as shown in Fig. 8. The resistivity increased drastically in the Ag-25Cu-65Ni (at.\%) alloy, whose microstructure consists of a $(\mathrm{Ni}, \mathrm{Cu})$ matrix with a fine $(\mathrm{Ag})$ dispersion. In such powder, effective liquid-phase sintering does not proceed. Figure 10 shows the calculated phase diagram at $1,500^{\circ} \mathrm{C}$ of the (a) Ag-Cu-Co and (b) Ag-Cu-Fe ternary systems. A stable miscibility gap in the liquid phase extends from the Ag-Co binary system in Ag-Cu-Co alloy. In the $\mathrm{Ag}-\mathrm{Cu}-\mathrm{Fe}$ system, the miscibility gap in the $\mathrm{Ag}-\mathrm{Fe}$ binary system is metastable below $1533^{\circ} \mathrm{C}$. The addition of $\mathrm{Cu}$, however, makes it stable in this isothermal section at $1500^{\circ} \mathrm{C}$. The in situ composite and egg-type microstructures were also obtained in these ternary systems in the same manner as with the Ag-Cu-Ni system. Results of composition analysis by EPMA measured on $\mathrm{Ag}-\mathrm{Cu}-\mathrm{Co}$ and $\mathrm{Ag}-\mathrm{Cu}-\mathrm{Fe}$ alloys are superimposed on Fig. 10a and b, respectively, and are consistent with the calculated equilibria between the immiscible liquid phases at $1500^{\circ} \mathrm{C}$. In both alloy systems, the compositions of the highest-Cu-content alloys shown by open triangles in Fig. 10a and b considerably deviate from the corresponding tie lines between solid triangles, which represent measured compositions of the immiscible phases. Such deviations seem to be caused by the decomposition of each immiscible liquid that occurred after the formation of the eggtype microstructure. EPMA measurements were carried out mainly on the Ag-rich and X-rich $(\mathrm{X}=\mathrm{Co}$ or $\mathrm{Fe}$ ) matrixes of the decomposed periphery and core, respectively, which results in the
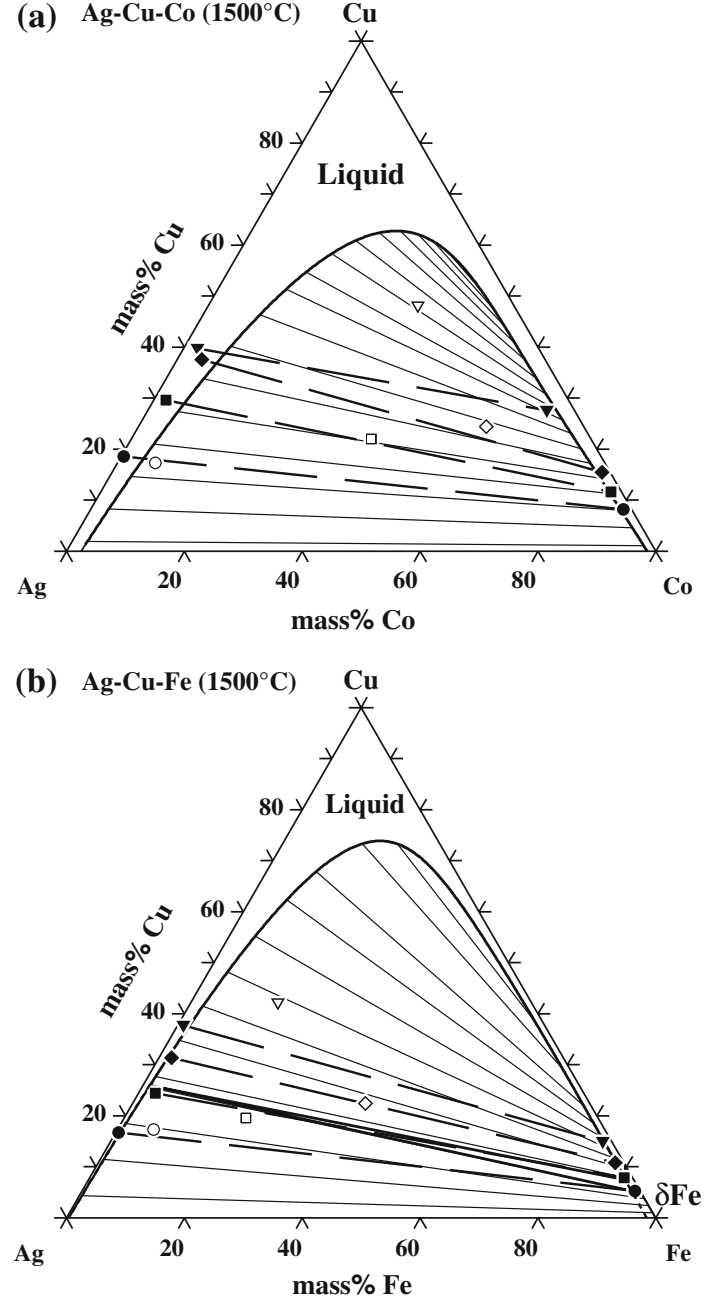

Fig. 10. Calculated liquid miscibility gaps of (a) Ag-Cu-Co and (b) Ag-Cu-Fe systems at $1500^{\circ} \mathrm{C}$. A metastable miscibility gap of the $\mathrm{Ag}-\mathrm{Cu}-\mathrm{Fe}$ system at low $\mathrm{Cu}$ content is shown by thick dashed curves. Composition of the gas-atomized alloys and results of EPMA measured at two immiscible phases are superimposed by open and solid symbols, respectively, which are consistent with the stable/ metastable miscibility gaps.

systematic errors in the measurements, especially in the high- $\mathrm{Cu}$ alloys. According to the microstructure examinations of the gas-atomized particles of $\mathrm{Ag}-\mathrm{Cu}-\mathrm{X}(\mathrm{X}=\mathrm{Ni}, \mathrm{Co}$ or $\mathrm{Fe})$ alloys, shown by symbols in Fig. 11, the morphology of the powder is schematically summarized in Fig. 11 . The in situ composite and egg-type micropowders can be produced from immiscible liquid alloys whose composition is located near both ends and around the middle of the miscibility gap, respectively. In between these two composition regions shown by the shaded areas in Fig. 11, mixed powder of in situ composite and eggtype microstructures can be obtained. The boundaries of each morphology region were roughly determined based on the experimental results. In addition to those morphologies, a dendritic microstructure was obtained from the samples whose chemical composition is outside of each miscibility 

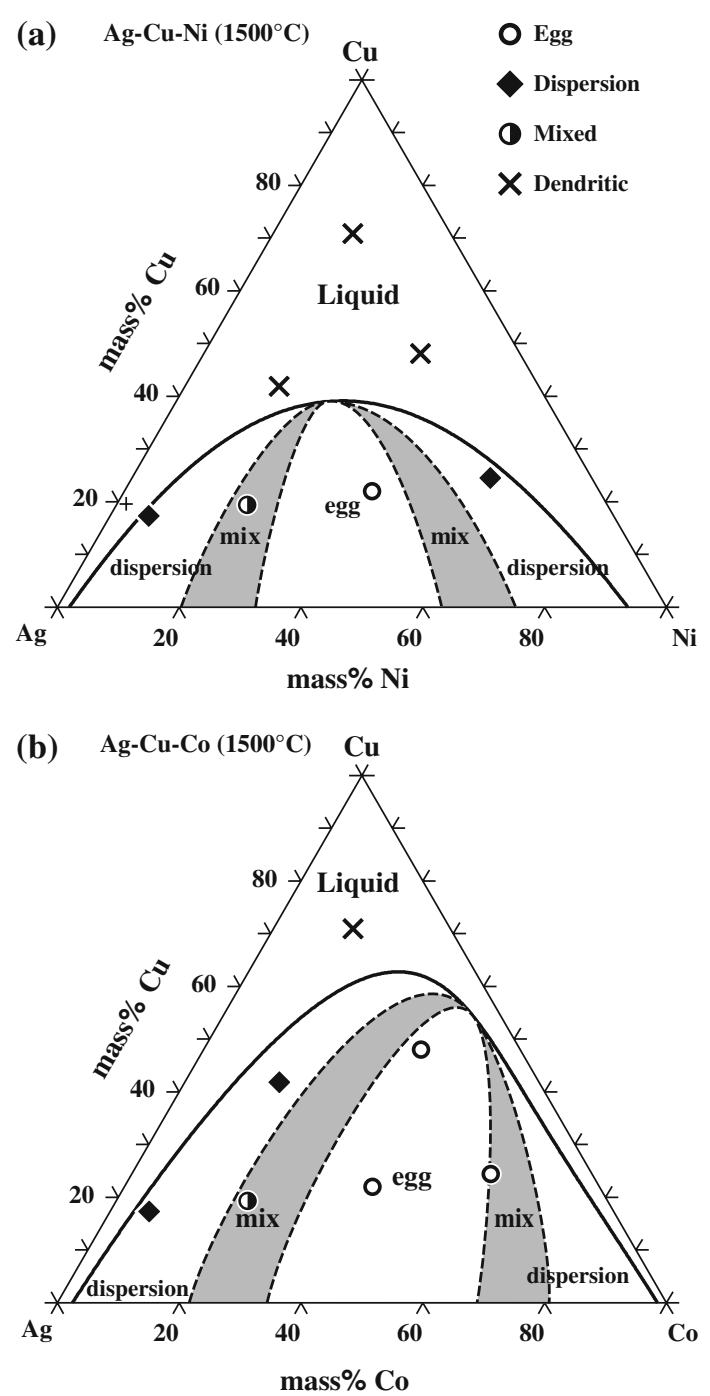

(c) Ag-Cu-Fe $\left(1500^{\circ} \mathrm{C}\right.$ : Stable \& Metastable $)$

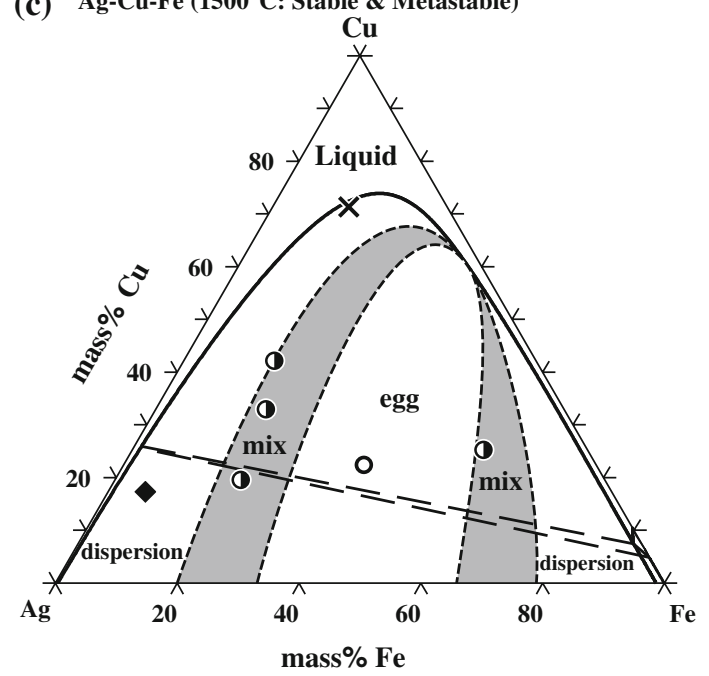

Fig. 11. Microstructural evolution related to liquid miscibility gap in (a) Ag-Cu-Ni, (b) Ag-Cu-Co, and (c) Ag-Cu-Fe systems.

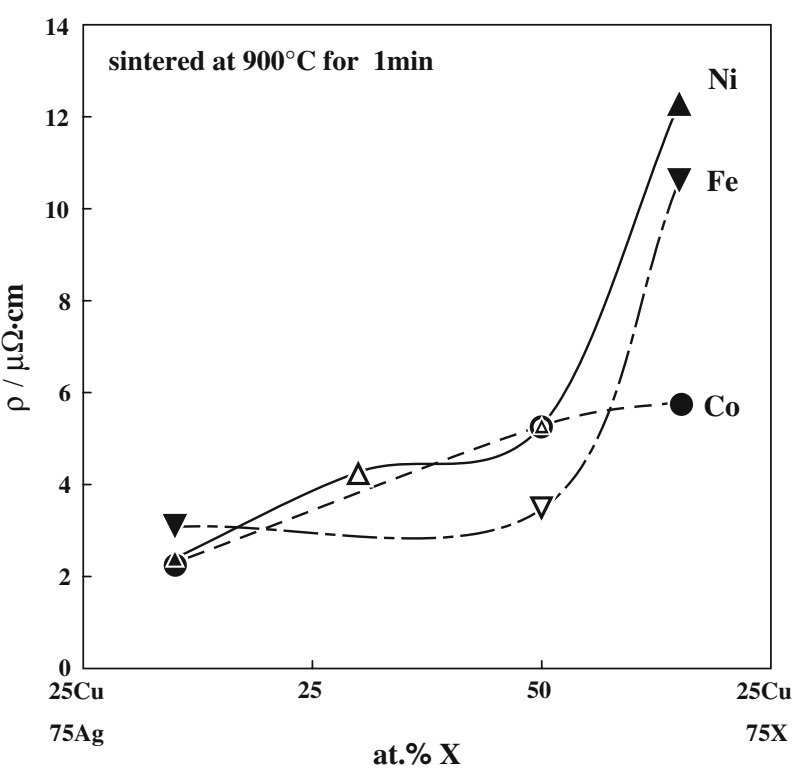

Fig. 12. Electrical resistivity of $\mathrm{Ag}-25 \mathrm{Cu}-\mathrm{X}(\mathrm{X}=\mathrm{Ni}, \mathrm{Fe}, \mathrm{Co})$ (at.\%) alloys.

gap at $1500^{\circ} \mathrm{C}$. These morphologies depend not only on the chemical composition but also possibly on the size of gas-atomized particles, the diameter of which ranges from $1 \mu \mathrm{m}$ to $100 \mu \mathrm{m}$ with maximum frequency around $25 \mu \mathrm{m}$. In this study, however, the size effect on the microstructure is not taken into account; it will be discussed in the future.

$\mathrm{Ag}-\mathrm{Cu}-\mathrm{Co}$ and $\mathrm{Ag}-\mathrm{Cu}-\mathrm{Fe}$ alloys were compacted and sintered at $900^{\circ} \mathrm{C}$ for $1 \mathrm{~min}$. The electrical resistivity of the sintered samples was measured, and the results are summarized in Fig. 12. Solid and open symbols represent that the precursor powder had a fine dispersion microstructure and egg-type morphology, respectively. In both alloy systems, the resistance increased with decreasing Ag content. Especially, fine-dispersion powders with a Ni-rich or Fe-rich matrix brought about a drastic increase of the resistance. Both the resistivity and $\mathrm{Ag}$ consumption were optimized in the $\mathrm{Ag}-25 \mathrm{Cu}-$ $50 \mathrm{Fe}$ (at.\%) alloy.

\section{Summary}

The microstructure of alloys with liquid miscibility gaps in Pb-free solders and Ag-based electroconductive filler were studied. The results obtained were as follows:

- The characteristic morphology of an egg-like core type and a uniform second-phase dispersion was confirmed and predicted in relation to the phase diagram.

- The egg-type microsolders of Sn-Al-Cu and Bi-Cu Sn powders are proposed as a new type of BGA 
packaging with melting temperatures of about $230^{\circ} \mathrm{C}$ and $270^{\circ} \mathrm{C}$, respectively.

- The microstructure of alloy powder in the Ag-Cu-X $(\mathrm{X}=\mathrm{Ni}, \mathrm{Co}, \mathrm{Fe})$ systems was found to be characterized by a liquid-phase miscibility gap.

- The Ag-Cu-X (X = Ni, Co, Fe) alloys with an eggtype microstructure show very low electrical resistivity after liquid-phase sintering.

Calculation of phase diagrams is a powerful tool for the microstructural design of alloy powder with a liquid miscibility gap, making it possible to predict the stable and metastable miscibility gaps in detail, the chemical compositions and phase fractions of two immiscible phases, etc.; it can also be utilized in the phase-field simulation of microstructure evolution.

\section{REFERENCES}

1. L. Ratke and S. Diefenbach, Mater. Sci. Eng. R15, 263 (1995).

2. J. Gröbner and R. Schmid-Fetzer, J. Met. 57, 19 (2005).

3. C.P. Wang, X.J. Liu, I. Ohnuma, R. Kainuma, and K. Ishida, Science 297, 990 (2002). doi:10.1126/science.1073050.

4. C. Marangoni, Ann. Phys. Chem. 143, 337 (1871).

5. J.Z. Zhao, J. He, Z.Q. Hu, and L. Ratke, Z. Metallkd. 95, 362 (2004).

6. M. Wu, A. Ludwig, and M. Peizer, U. Postl. Adv. Eng. Mater. 7, 846 (2005).

7. J. He, J.Z. Zhao, and L. Ratke, Acta Mater. 54, 1749 (2006). doi:10.1016/j.actamat.2005.12.023.

8. G. Kapty, J. Mater. Sci. 40, 2175 (2005).
9. C.P. Wang, X.J. Liu, Y. Takaku, I. Ohnuma, R. Kainuma, and K. Ishida, Metall. Mater. Trans. A 35A, 1243 (2004). doi:10.1007/s11661-004-0298-y.

10. C.P. Wang, X.J. Liu, R.P. Shi, C. Chen, Y. Wang, I. Ohnuma, R. Kainuma, and K. Ishida, Appl. Phys. Lett. 91, 141904 (2007). doi:10.1063/1.2794415.

11. X. Liu, D. Qiu, M. Guo, and Z. Yang, J. Chin. Polym. Sci. 23, 561 (2005).

12. I. Ohnuma, X.J. Liu, H. Ohtani, and K. Ishida, J. Electron. Mater. 28, 1163 (1999). doi:10.1007/s11664-999-0152-5.

13. X.J. Liu, K. Oikawa, I. Ohnuma, R. Kainuma, and K. Ishida, J. Met. 55, 53 (2003).

14. C.P. Wang, X.J. Liu, M. Jiang, I. Ohnuma, R. Kainuma, and K. Ishida, J. Phys. Chem. Solids 66, 246 (2005). doi:10.1016/ j.jpcs.2004.08.039.

15. E. Bradley and K. Banerji, IEEE Trans. Components Packag. Manuf. Technol. B19, 320 (1996). doi:10.1109/96.496035.

16. F. Guo and K.N. Subramanian, Adv. Mater. Proc. 160, 41 (2002).

17. R.P. Shi, C.P. Wang, X.J. Liu, C. Shen, and Y. Wang, Abstracts of CALPHAD XXXVII, Saariselkä, Finland, 15-20 June, 2008, p. 32.

18. K. Uenishi, Y. Kohara, S. Sakatani, T. Saeki, K.F. Kobayashi, and M. Yamamoto, Mater. Trans. 43, 1833 (2002). doi:10.2320/matertrans.43.1833.

19. Y. Takaku, I. Ohnuma, R. Kainuma, Y. Yamada, Y. Yagi, Y. Nishibe, and K. Ishida, J. Electron. Mater. 35, 1926 (2006). doi:10.1007/s11664-006-0295-6.

20. Y. Yamada, Y. Takaku, Y. Yagi, Y. Nishibe, I. Ohnuma, Y. Sutou, R. Kainuma, and K. Ishida, Microelectron. Reliab. 46, 1932 (2006). doi:10.1016/j.microrel.2006.07.083.

21. Y. Yamada, Y. Takaku, Y. Yagi, I. Nakagawa, T. Atsumi, M. Shirai, I. Ohnuma, and K. Ishida, Microelectron. Reliab. 47, 2147 (2007). doi:10.1016/j.microrel.2007.07.102.

22. L.E. Murr, Interfacial Phenomena in Metals and Alloys (Reading, MA: Addison-Wesley, 1975), p. 100. 